\title{
Is glassiness a common characteristic of soil organic matter?
}

\section{Supporting Information}

\author{
JULIA HuRRAß AND GABRIELE E. SCHAUMANN ${ }^{*}$
}

\section{Contents:}

- Baseline correction

- Fig. SI-1. DSC baseline corrections for air-dried samples of the different sample groups (F: $\mathrm{O}_{\mathrm{h}}$ horizon of the forest location F4, C: $A_{h 1}$ horizon of the location Chorin, S: $A_{h}$ horizon of the southern taiga, T: Tiergarten sample, B: Buch sample). The upper graph shows the original DSC curves (first run: solid line, second run: dashed line). The graph below shows the DSC curves after baseline correction (subtraction of the second run from the first run).

- Fig. SI-2. DSC thermograms, which are difficult to evaluate, of an air-dried $A_{h}$ sample of the southern taiga in Siberia (S) and an air-dried sample from the Tiergarten (T). The upper graph shows the original DSC curves (first run: solid line, second run: dashed line). The graph below shows the DSC curves after baseline correction (subtraction of the second run from the first run).

- Temperature-modulated DSC (MDSC)

- Fig. SI-3. Representative MDSC thermogram of the air-dried $\mathrm{O}_{\mathrm{h}}$ sample of the forest location F1.

- Fig. SI-4. DSC thermograms of air-dried and bromine-oxidized samples (C: $A_{h 1}$ horizon of the location Chorin $\left(7.5 \% \mathrm{OM}\right.$ after oxidation), $\mathrm{S}: \mathrm{A}_{\mathrm{h}}$ horizon of the southern taiga in Siberia (11.4\% OM after oxidation)). For the $A_{h 1}$ sample of the location Chorin $(C)$, the glass transition of the water-free sample after a thermal pretreatment (open pan) is shown additionally. With the exception of the measurement in the open pan, the graph shows the DSC curves after baseline correction (subtraction of the second run from the first run).

- Effect of wet-chemical oxidation on the glass transition-like step transitions

- Thermogravimetry

- Fig. SI-5. Representative DTG and DTA signal of the air-dried $\mathrm{A}_{\mathrm{h} 1}$ sample of the location Chorin.

- Tab. SI-1. Weight losses of the three characteristic temperature ranges (peaks 1-3) of the studied samples. For each sample, the limits of the temperature ranges were chosen corresponding to the minima between the peaks in the DTA signal.

- Interrelation with black carbon

- Fig. SI-6. Change of the specific heat capacity which is related to the mass of SOM $\left(\triangle C_{O M}\right)$ as a function of the ratio of the weight loss above $375^{\circ} \mathrm{C}$ (assumed to be related to BC) and the OM content of the samples from Siberia, Tiergarten and Buch. The Siberia samples are divided into Chernozems and Luvisols.

\footnotetext{
* Corresponding author phone: +49(30)314-73173; fax: +49(30)314-29319; email: Gabi.Schaumann@TU-Berlin.DE
} 


\section{Baseline correction}

For most samples, the thermogram of the second heating run reveals a comparable curvature as the first one, but shows no step transition. In some cases, part of the endothermic peak persists in the second runs $\left(\mathrm{O}_{\mathrm{f}}\right.$ and $\mathrm{O}_{\mathrm{h}}$ horizons in Fig. 1, POM and MOM fractions of the $\mathrm{O}_{\mathrm{h}}$ horizon in Fig. 3 and $\mathrm{O}_{\mathrm{h}}$ horizon from the forest location F4 in Fig. SI-1). However, these thermograms do not reveal a step and are thus judged appropriate for baseline correction in order to improve the evaluability of $T_{g}{ }^{*}$ and $\Delta C$. Consequently, after subtracting the second from the first runs, the resulting overshoot peaks may be smaller than in the original thermograms, but $\Delta C$ is unaffected. The nature of this persistent endothermic peak will be described in a separate publication.

Only for some measurements, the curve progressions of the first and the second run were not parallel in the whole temperature range. Especially for the temperatures above $100{ }^{\circ} \mathrm{C}$, evaporation of water may cause different curvatures of the consecutive runs. In Fig. SI-2, two DSC thermograms yielding transition regions, which are difficult to evaluate due to the non-parallel curve progressions of the subsequent runs, are shown exemplarily. Nevertheless, the comparison of both runs indicate a step transition. Differences in curvature between first and second run cause remaining curvatures in the resulting difference curves (Fig. SI-2). In such curved thermograms, the choice of the limits for the evaluation of the step transitions is difficult and influences the results for $T_{g}{ }^{*}$ and $\Delta C$. In these cases, the DSC measurements were repeated.

Baseline correction for the humic fractions. Since no second run could be calculated for the calculated sum curve, the thermograms in Fig. 4 in the main text are not baseline-corrected to better compare the respective thermograms. The curvature of the original thermograms, which is strongly pronounced for the fulvic acid, the humic acid and the carbohydrate fractions as well as for the calculated sum curve, may result in high errors for $T_{g}{ }^{*}$ and $\Delta C$, but the principal observation of a step accompanied by an endothermic peak is unaffected. 


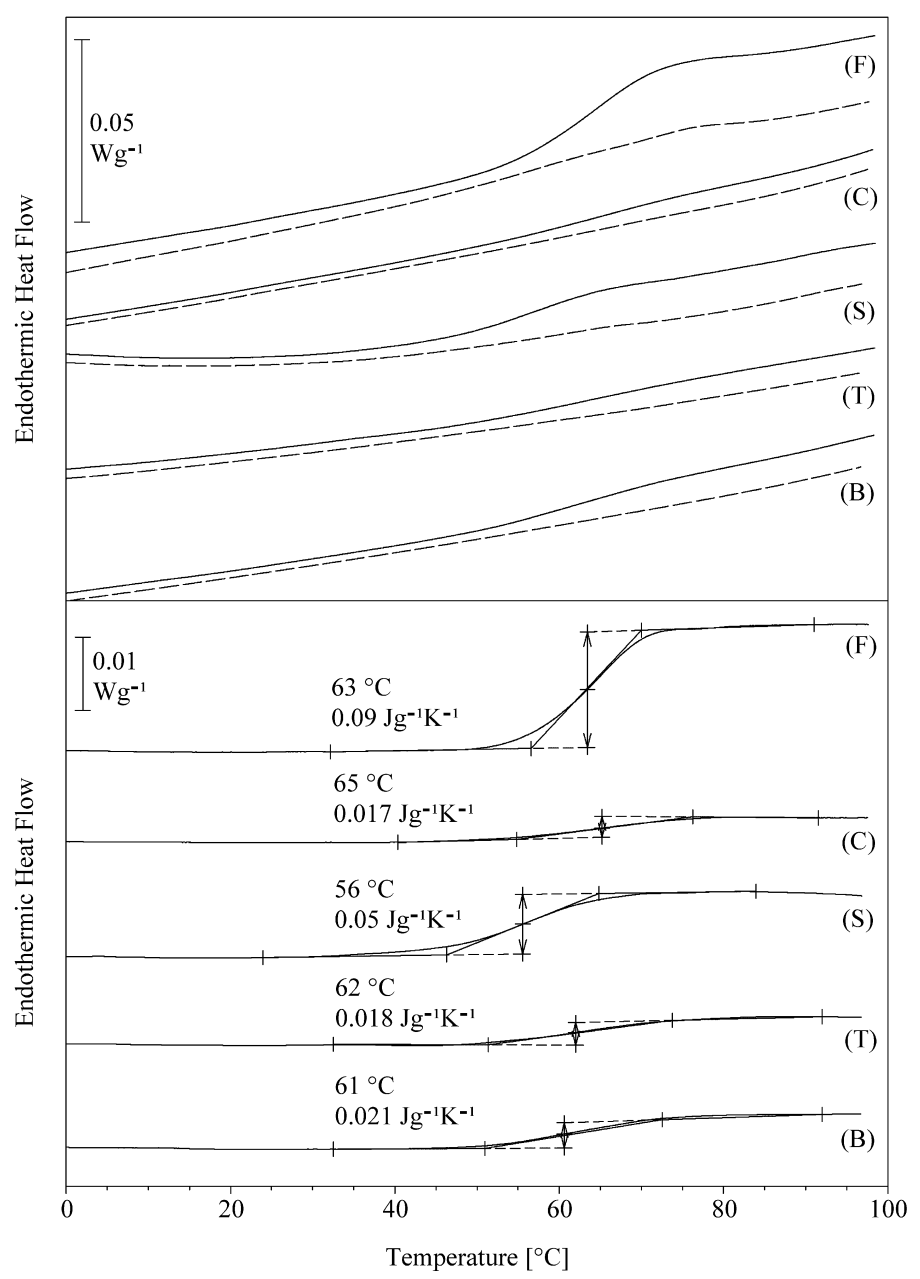

Fig. SI-1. DSC baseline corrections for air-dried samples of the different sample groups (F: $\mathrm{O}_{\mathrm{h}}$ horizon of the forest location F4, C: $A_{h 1}$ horizon of the location Chorin, S: $A_{h}$ horizon of the southern taiga, T: Tiergarten sample, B: Buch sample). The upper graph shows the original DSC curves (first run: solid line, second run: dashed line). The graph below shows the DSC curves after baseline correction (subtraction of the second run from the first run). 


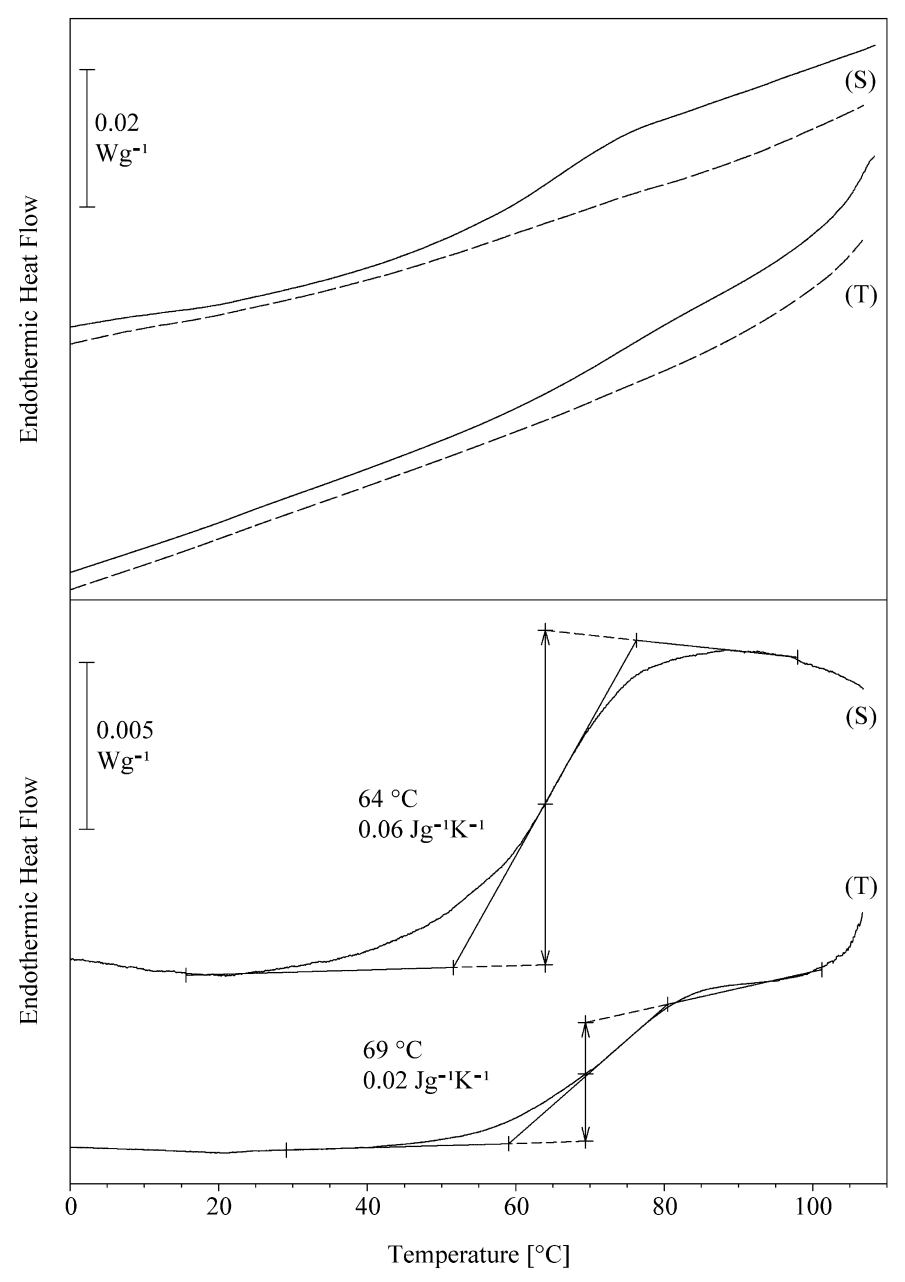

Fig. SI-2. DSC thermograms, which are difficult to evaluate, of an air-dried $A_{h}$ sample of the southern taiga in Siberia (S) and an air-dried sample from the Tiergarten (T). The upper graph shows the original DSC curves (first run: solid line, second run: dashed line). The graph below shows the DSC curves after baseline correction (subtraction of the second run from the first run). 


\section{Temperature-modulated DSC (MDSC)}

Experimental. For the temperature-modulated DSC measurements between $-50{ }^{\circ} \mathrm{C}$ and $110{ }^{\circ} \mathrm{C}$, the heating rate of $2.5 \mathrm{~K} \mathrm{~min}^{-1}$ was modulated by a sinusoidal oscillation with $90 \mathrm{~s}$ modulation period and $\pm 2{ }^{\circ} \mathrm{C}$ temperature amplitude. By means of Fourier transformation, the total heat flow can be divided into a reversing and a non-reversing heat flow. In this way, a differentiation between fast processes (reversing heat flow) and slow processes (non-reversing heat flow) is possible. Classical glass transitions reveal reversing characteristics, and structural relaxation and evaporation are non-reversing processes (SI-1,SI-2). The MDSC thermograms were not baseline-corrected.

Results. While it is difficult to decide whether the transitions in the total heat flow represent a step transition or rather solely an endothermic peak, the reversing and the non-reversing heat flow show a step transition, which is accompanied by a distinct enthalpic overshoot peak in the non-reversing heat flow (Fig. SI-3). The transition intensity of all investigated samples is divided into contributions of the reversing and the non-reversing heat flows. For the $\mathrm{O}_{\mathrm{h}}$ horizon of the forest location $\mathrm{F} 1$, the contributions of both heat flows to $\Delta C$ are comparable.

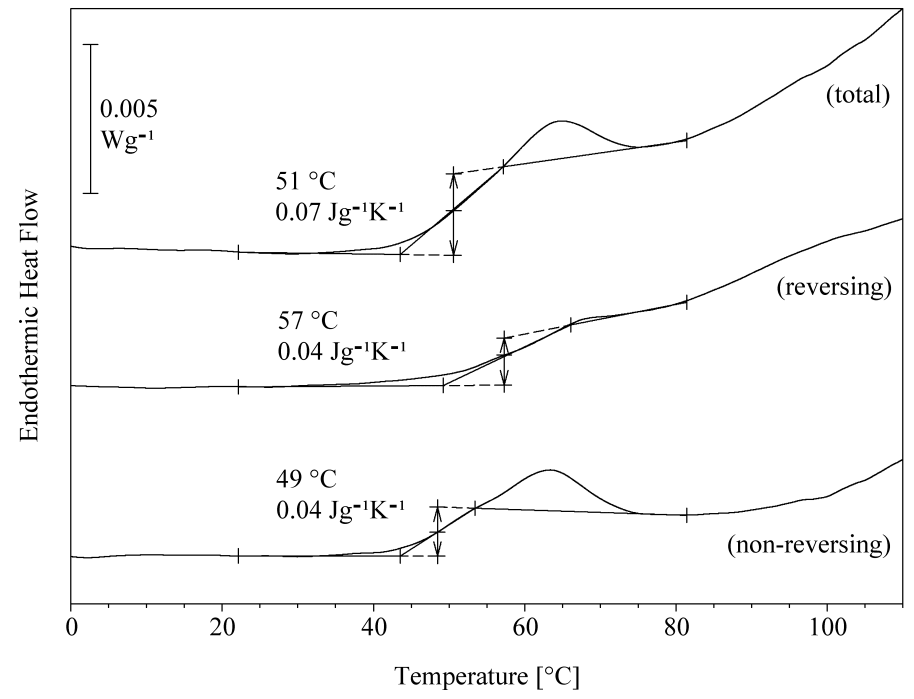

Fig. SI-3. Representative MDSC thermogram of the air-dried $O_{h}$ sample of the forest location F1. 


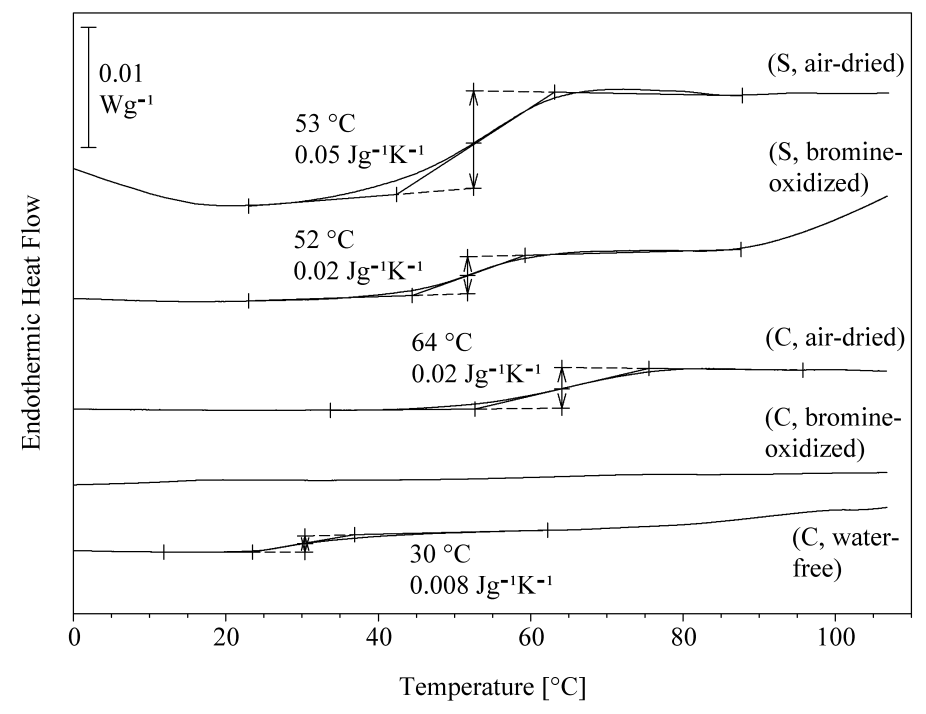

Fig. SI-4. DSC thermograms of air-dried and bromine-oxidized samples (C: $A_{h 1}$ horizon of the location Chorin (7.5\% OM after oxidation), S: $A_{h}$ horizon of the southern taiga in Siberia (11.4\% OM after oxidation)). For the $A_{h 1}$ sample of the location Chorin (C), the glass transition of the water-free sample after a thermal pretreatment (open pan) is shown additionally. With the exception of the measurement in the open pan, the graph shows the DSC curves after baseline correction (subtraction of the second run from the first run).

\section{Effect of wet-chemical oxidation on the glass transition-like step transitions}

Experimental. Wet-chemical oxidation by $\mathrm{H}_{2} \mathrm{SO}_{4}(97 \%), \mathrm{H}_{2} \mathrm{O}_{2}(30 \%)$ or bromine was performed to investigate the effect of OM removal on the step transitions. The soil samples were brought into contact with the oxidants for 9 days under stirring (at $50{ }^{\circ} \mathrm{C}$ for $\mathrm{H}_{2} \mathrm{O}_{2}$ and $20{ }^{\circ} \mathrm{C}$ for $\mathrm{H}_{2} \mathrm{SO}_{4}$ and bromine). The remaining bromine then was destroyed by sodium thiosulfate. After filtration, the oxidized samples were washed with distilled water and dried at $105{ }^{\circ} \mathrm{C}$. The oxidation with $\mathrm{H}_{2} \mathrm{SO}_{4}$ and bromine was carried out with all Siberia samples, one Chorin sample and one Buch sample. Due to the poor result (destruction of $19 \% \mathrm{OM}$ related to the loss on ignition), the $\mathrm{H}_{2} \mathrm{SO}_{4}$ oxidation was performed only with one Buch sample.

Results. The oxidants $\mathrm{H}_{2} \mathrm{SO}_{4}, \mathrm{H}_{2} \mathrm{O}_{2}$ and bromine destroyed less organic material than the dry combustion. For most samples, the degree of efficiency increased in the order $\mathrm{H}_{2} \mathrm{SO}_{4}$, bromine and $\mathrm{H}_{2} \mathrm{O}_{2}$. On average, the removal of OM amounts to $(37 \pm 10) \%$ for bromine and $(55 \pm 20) \%$ for $\mathrm{H}_{2} \mathrm{O}_{2}$ related to the loss on ignition. Only if the OM contents were reduced below $10 \%$, no glass-transition- 
like step transitions were detected any more in the DSC thermograms (see $A_{h 1}$ sample of the location Chorin in Fig. SI-4). For the samples which still reveal OM contents above $10 \%$ after oxidation, there is a weak correlation between the OM contents and the $\Delta C$ values of the step transitions $(\mathrm{P}<0.004)$.

\section{Thermogravimetry}

Experimental. Thermogravimetry (TG) was conducted with a Mettler Toledo STGA 851e thermogravimetric system (Mettler Toledo, Switzerland) under dry air at a flow rate of $200 \mathrm{~mL} \mathrm{~min}^{-1}$. 0.2 to $1 \mathrm{~g}$ of the sample were placed into a ceramics crucible with an $\mathrm{Al}_{2} \mathrm{O}_{2}$ filled crucible used as a reference. The sample was heated with $5 \mathrm{~K} \mathrm{~min}^{-1}$ from $25^{\circ} \mathrm{C}$ to $950{ }^{\circ} \mathrm{C}$. In the resulting thermograms, the first derivative of the sample weight (DTG) and the differential thermal analysis (DTA) signal are plotted as a function of temperature. TG measurements were carried out for one Chorin sample, all Siberia samples, 14 Tiergarten and 38 Buch samples.

Results. The TG thermograms of the different soil samples indicate three temperature ranges of distinct weight losses (Fig. SI-5), which is in consistence with classic thermogravimetric behavior of SOM (SI-3-SI-6). The weight loss between $25^{\circ} \mathrm{C}$ and $165^{\circ} \mathrm{C}$ is caused by the water, which has remained in the sample despite of the previous tempering at $120{ }^{\circ} \mathrm{C}$. The DTG peak between $130{ }^{\circ} \mathrm{C}$ and $320{ }^{\circ} \mathrm{C}$ is related to exothermic decarboxylation and dehydration reactions of thermolabile compounds like fatty acids, peptides, carbohydrates, cellulose and hemicellulose. The exothermic process between $320{ }^{\circ} \mathrm{C}$ and $600{ }^{\circ} \mathrm{C}$ is due to the decomposition of thermostable SOM compounds with high $\mathrm{C} / \mathrm{H}$ ratios (e.g. condensed aromatic nuclei) or the destruction of organo-mineral complexes. Tab. SI-1 summarizes the weight losses of the three temperature ranges for all the studied samples. 


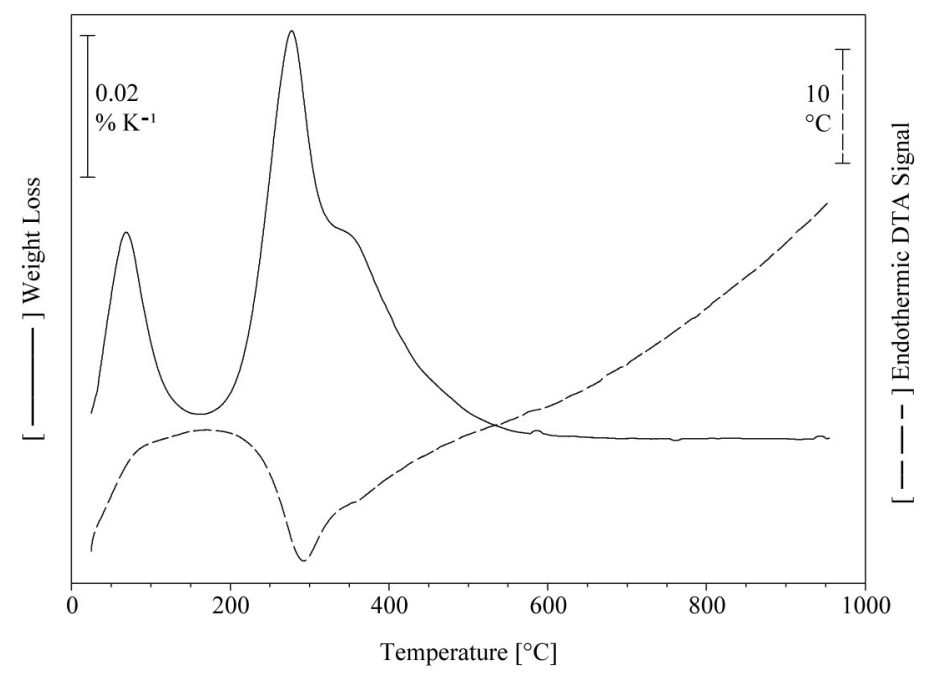

Fig. SI-5. Representative DTG and DTA signal of the air-dried $A_{h 1}$ sample of the location Chorin.

Tab. SI-1. Weight losses of the three characteristic temperature ranges (peaks 1-3) of the studied samples. For each sample, the limits of the temperature ranges were chosen corresponding to the minima between the peaks in the DTA signal.

\begin{tabular}{|c|c|c|c|c|c|c|c|c|c|c|}
\hline $\begin{array}{l}\text { Sample } \\
\text { group }\end{array}$ & $\begin{array}{l}\text { location, } \\
\text { horizon }\end{array}$ & $\begin{array}{c}\text { peak 1 } \\
\text { start } \\
{\left[{ }^{\circ} \mathrm{C}\right]}\end{array}$ & $\begin{array}{c}\text { peak } 1 \\
\text { end } \\
{\left[{ }^{\circ} \mathrm{C}\right]}\end{array}$ & $\begin{array}{c}\text { peak } 1 \\
\text { weight } \\
\text { loss [\%] }\end{array}$ & $\begin{array}{c}\text { peak 2 } \\
\text { start } \\
{\left[{ }^{\circ} \mathrm{C}\right]}\end{array}$ & $\begin{array}{c}\text { peak } 2 \\
\text { end } \\
{\left[{ }^{\circ} \mathrm{C}\right]}\end{array}$ & $\begin{array}{c}\text { peak } 2 \\
\text { weight } \\
\text { loss [\%] }\end{array}$ & $\begin{array}{c}\text { peak 3 } \\
\text { start } \\
{\left[{ }^{\circ} \mathrm{C}\right]}\end{array}$ & $\begin{array}{c}\text { peak } 3 \\
\text { end } \\
{\left[{ }^{\circ} \mathrm{C}\right]}\end{array}$ & $\begin{array}{c}\text { peak } 3 \\
\text { weight } \\
\text { loss [\%] }\end{array}$ \\
\hline \multirow{6}{*}{$\mathrm{C}$} & Chorin, $\mathrm{O}_{\mathrm{f}}$ & 25 & 150 & $6.4 \pm 0.1$ & 150 & 340 & $20.7 \pm 0.1$ & 340 & 600 & $12.3 \pm 0.1$ \\
\hline & Chorin, $A_{h 1}$ & 25 & 165 & $1.8 \pm 0.1$ & 165 & 320 & $4.2 \pm 0.3$ & 320 & 600 & $3.1 \pm 0.3$ \\
\hline & Chorin, $A_{h 2}$ & 25 & 165 & $0.9 \pm 0.1$ & 165 & 320 & $1.6 \pm 0.1$ & 320 & 600 & $1.3 \pm 0.1$ \\
\hline & $\begin{array}{l}\text { Chorin, } \\
\left(B_{v}\right) A_{h}\end{array}$ & 25 & 165 & $0.9 \pm 0.1$ & 165 & 320 & $1.3 \pm 0.1$ & 320 & 600 & $2 \pm 1$ \\
\hline & $\begin{array}{l}\text { Chorin, } \\
B_{v}\left(A_{h}\right)\end{array}$ & 25 & 165 & $0.8 \pm 0.1$ & 165 & 330 & $1.0 \pm 0.1$ & 330 & 600 & $0.8 \pm 0.1$ \\
\hline & Chorin, $B_{v}$ & 25 & 165 & $0.5 \pm 0.1$ & 165 & 340 & $0.4 \pm 0.1$ & 340 & 600 & $0.4 \pm 0.1$ \\
\hline \multirow{5}{*}{ S } & $\begin{array}{l}\text { southern } \\
\text { taiga, O }\end{array}$ & 25 & 170 & $12 \pm 2$ & 170 & 320 & $29 \pm 4$ & 320 & 600 & $24 \pm 2$ \\
\hline & $\begin{array}{l}\text { southern } \\
\text { taiga, } A_{h}\end{array}$ & 25 & 190 & $6 \pm 2$ & 190 & 330 & $7 \pm 3$ & 330 & 600 & $7 \pm 2$ \\
\hline & $\begin{array}{l}\text { forest } \\
\text { steppe, } A_{h}\end{array}$ & 25 & 200 & $7 \pm 2$ & 200 & 340 & $6.7 \pm 0.7$ & 340 & 600 & $7 \pm 2$ \\
\hline & $\begin{array}{l}\text { mountain } \\
\text { forest } \\
\text { steppe, } A_{h}\end{array}$ & 25 & 180 & $4.4 \pm 0.2$ & 180 & 330 & $6.0 \pm 0.2$ & 330 & 188 & $5.3 \pm 0.2$ \\
\hline & steppe, $\mathrm{A}_{\mathrm{h}}$ & 25 & 200 & $5.5 \pm 0.4$ & 200 & 350 & $7 \pm 1$ & 350 & 600 & $6 \pm 1$ \\
\hline $\mathrm{T}$ & Tiergarten & 25 & 175 & $1.9 \pm 0.3$ & 175 & 315 & $4 \pm 1$ & 315 & 600 & $3 \pm 1$ \\
\hline B & Buch & 25 & 175 & $2.1 \pm 0.2$ & 175 & 340 & $4.3 \pm 0.4$ & 340 & 600 & $3.3 \pm 0.3$ \\
\hline
\end{tabular}




\section{Interrelation with black carbon}

To obtain first indications whether black carbon may be responsible for the observed glass transitionlike step transition, we divided the TG weight losses (Fig. SI-5) into a non-BC portion between $200{ }^{\circ} \mathrm{C}$ and $375{ }^{\circ} \mathrm{C}$ and a $\mathrm{BC}$ portion above $375^{\circ} \mathrm{C}$, in analogy to the thermal oxidation method applied by Cornelissen et al. (SI-7). No significant correlation between the weight losses above $375{ }^{\circ} \mathrm{C}$ and the $\Delta C_{O M}$ values was detected (Fig. SI-6). This may be due to either the absence of BC contribution to the transitions or to methodical restrictions, as (i) the combustion time in TG differs from that used by Cornelissen et al. (SI-7) or (ii) the combustion produces new thermostable substances above $375{ }^{\circ} \mathrm{C}$ which may reveal glassy character, but are not present in the samples before the combustion. For a definitive evidence of an interrelation between BC and the step transition characteristics, more detailed studies are required.

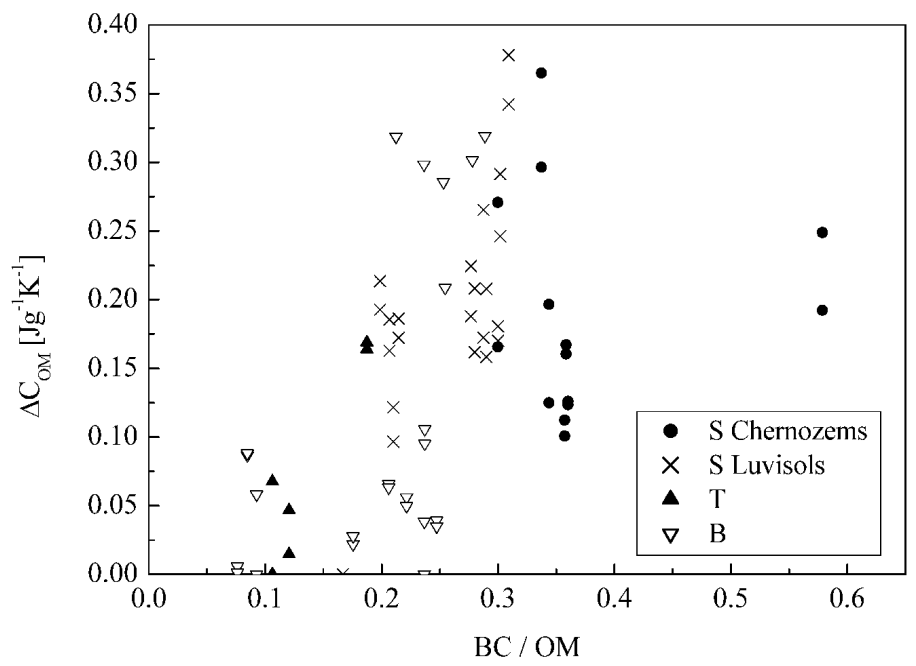

Fig. SI-6. Change of the specific heat capacity which is related to the mass of SOM $\left(\Delta C_{O M}\right)$ as a function of the ratio of the weight loss above $375^{\circ} \mathrm{C}$ (assumed to be related to BC) and the OM content of the samples from Siberia, Tiergarten and Buch. The Siberia samples are divided into Chernozems and Luvisols. 


\section{References}

(1) Hutchinson, J. M. Characterizing the glass transition and relaxation kinetics by conventional and temperature-modulated differential scanning calorimetry. Thermochim. Acta 1998, 324, 165-174.

(2) Young, K. D.; LeBoeuf, E. J. Glass transition behavior in a peat humic acid and an aquatic fulvic acid. Environ. Sci. Technol. 2000, 34, 4549-4553.

(3) Cuypers, C.; Grotenhuis, T.; Nierop, K. G. J.; Franco, E. M.; de Jager, A.; Rulkens, W. Amorphous and condensed organic matter domains: The effect of persulfate oxidation on the composition of soil/sediment organic matter. Chemosphere 2002, 48, 919-931.

(4) Shurygina, E. A.; Larina, N. K.; Chubarova, M. A.; Kononova, M. M. Differential thermal analysis and thermogravimetry of soil humus substances. Sov. Soil Sci. 1971, 35-44.

(5) Zuyi, T.; Shifang, L.; Fan, Z. Z.; Yuhui, Y. Thermal transformation of humic and fulvic acids in soils. Part 2. Thermogravimetry. Chem. Ecol. 1997, 14, 21-30.

(6) Schulten, H.-R.; Leinweber, P.; Sorge, C. Composition of organic matter in particle-size fractions of an agricultural soil. J. Soil Sci. 1993, 44, 677-691.

(7) Cornelissen, G.; Kukulska, Z.; Kalaitzidis, S.; Christanis, K.; Gustafsson, O. Relations between environmental black carbon sorption and geochemical sorbent characteristics. Environ. Sci. Technol. 2004, 38, 3632-3640. 